\title{
Graduation Design's Topic Selection and Ability Cultivation of Engineering Management Major
}

\author{
Liming $\mathrm{Wu}$ \\ College of Hydraulic and Environmental Engineering \\ Three Gorges University \\ Hubei Yichang, China \\ wlming@ctgu.edu.cn
}

\author{
Qi Guo \\ College of Hydraulic and Environmental Engineering \\ Three Gorges University \\ Hubei Yichang, China \\ guoqi@ctgu.edu.cn
}

\begin{abstract}
Selection of graduation design's topic of engineering management major should reflect professional training demands. Its depth, complexity and scope should be moderate, so does its design workload. Selection of the topic should be comprehensive, which means that it covers the basic professional theories and courses and aims at developing students' ability of comprehensively using the knowledge they learned and solving practical problems so that improve students' thinking, practical operation, adapt to society and self-management capabilities. Meanwhile the topic should be beneficial to culture the students' good habits of cooperation, hard-working and a good style of work in order to achieve the aims of exploiting students' potential and adapting faster to future work.
\end{abstract}

Keywords-project management; graduation design; selection of topics; capacity-building

\section{INTRODUCTION}

Graduation design is an important practice teaching links of undergraduate training program which enable students to apply what they have learned to practice. It is a competitive training experience for students and cannot be replaced by other teaching links. For the students the knowledge they have learned is isolated, purely theoretical, they don't know how to analyze and solve problems and the value of knowledge cannot be reflected. Graduation design is a comprehensive integration of the knowledge. Therefore, graduate design is a ruler of teaching. It not only developed the comprehensive usage ability of knowledge but also to reflect teaching and management problems.

\section{SELECTION PRINCIPLE OF GRADUATION DESIGN TOPICS}

Topic selection is the first step in graduate design teaching and design topics will largely determine graduation design outcomes. Therefore, a good graduation design topic is the basis of a good graduation design result. Design topic includes knowledge confines, methods and task and determines how much intelligence and time should the student devoted. Project Management is closely integrated with the practice and cultivates management talent who know both theoretical knowledge and engineering technology. Graduation design topics selection should consider the following principles.

(1) Topic selection shall meet the requirements of undergraduate training program and can not deviate from the direction of Project Management. Project management major of CTGU expertise on "Hydro" featuring. Design topic should based on hydropower project, supplemented by housing construction project. Topics should covered the "four platforms" and specialized courses that are technology platform courses, management platform courses, economic platform courses, laws and regulations platform courses and cost management courses. Successful knowledge fusion can be realized by the student to prepare a Tendering documents and pre-tender estimate.

(2) Topics should be combined with practice. There are three main topics of graduation design. First is practical engineering design topic, the second is theoretical and exploratory research topic, the third is typical topic[1]. Take consideration of the characteristics of engineering management, we choose practical engineering design topic, and require the students to make certain thematic analysis.

(3)The quantity, difficulty, depth of the topic should be moderate.

(4) Ensure the novelty of topics. Project management has the features of high specialization, technical updates fast so that it requires the selection of the topics should be timely updated.

(5) Cultivate comprehensive capability of students. Graduation design should not only develop the practical abilities of students, but also to develop students analytic skills capability.

\section{TOPICS SELECTION AND CAPACITY CULTIVATION}

Modern project has the features of large, technically complex, fast updating of knowledge, etc. In order to achieve the overall objective of the project requires coordinate multiple binding targets. That requires project management students have comprehensive ability. A qualified engineering 
management students should have four capabilities which can grouped into thinking ability, practical ability, social adaptability and self-management ability. Thinking ability including observation, imagination, thinking skills, analytic skills, information processing skills, adaptability, innovation, etc. Practical ability including identify problem ability, solve problem ability, data collection capability and knowledge apply ability (including computer operations, etc. ) etc. Social adaptability including interpersonal skill, communication skill (including language and written), teamwork ability. Self-management capability including self-learning ability, plan, patience, organizational skills and self-development capability [2] [3]. Ability structure as shown in Figure 1 .

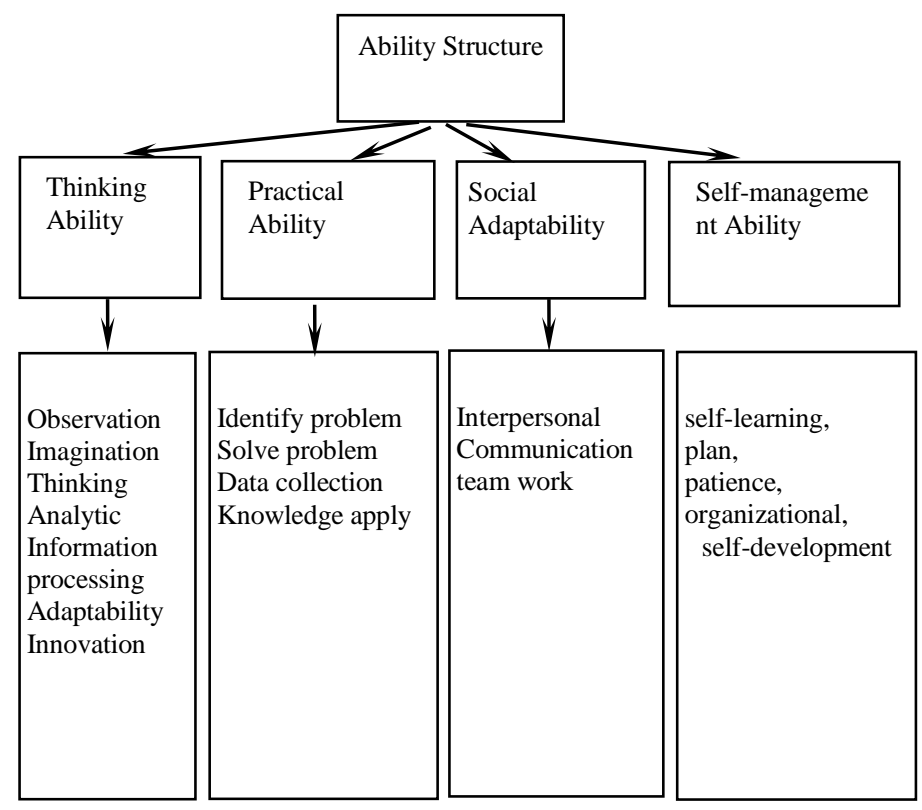

FIGURE I. COLLEGE STUDENTS’ BASIC ABILITY STRUCTURE DIAGRAM

Good topic is the prerequisites of good graduation results. Cultivation of students' comprehensive ability and quality of training need to rely upon graduation design. To achieve the purpose of cultivate students' comprehensive ability through internships, access to information, opening report, quantity computing, program selection and argumentation, pricing, thematic studies, writing a graduation design specification [4] .

\section{IMPLEMENTATION AND CONTROL OF GRADUATE DESIGN}

Three Gorges University has always attached great importance to practice teaching session of graduation design. Faculties and Teaching Departments both proceed management from the selection of topic to submitting outcome and thesis oral defense. The tutor put forward his own topics and department organize experts to examine these topics. After the dean of the department signing, the College organize supervision group to inspect and review the topics and propose amendments. Tutors rectify the topics and input them into graduation design topics systems. After the student choose one topic, mission statement issued to the students. Student can start graduation design according to the mission statement and design data. Tutor instruct and examine in all aspects of English translation ,opening report writing ,first draft ,revised draft, final version. The tutor should make detail record of guid process and examination results. Supervision group examine in all aspects of opening report writing, foreign language translation, oral defense. Graduate design control procedures in Figure 2.

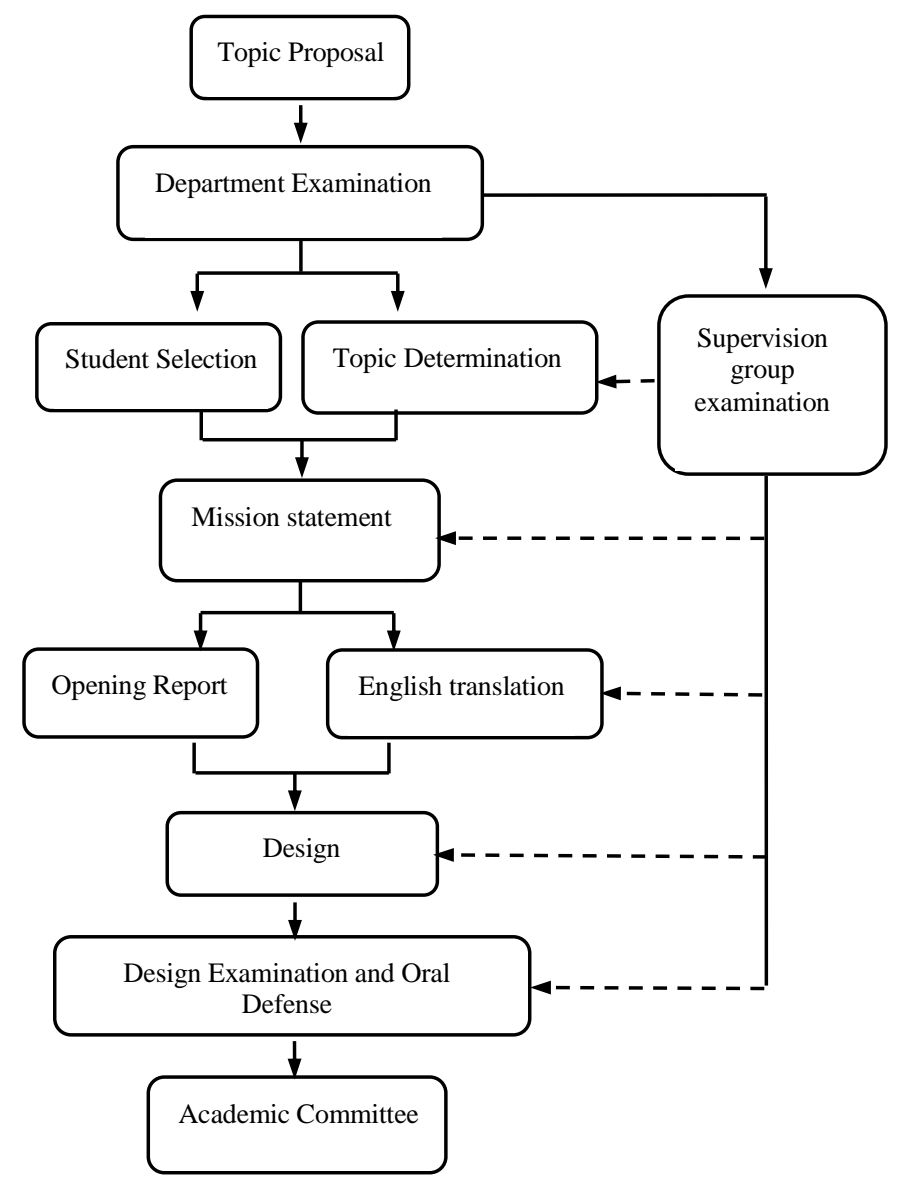

FIGURE II. GRADUATE DESIGN CONTROL PROCEDURES

\section{CONCLUSION}

Engineering Management graduate design topics should reflect the requirements of professional training programs. Depth, breadth and difficulty should be moderate. The quantity and schedule of graduation design should be appropriates. The topic should be comprehensive and which can cover the basic theory and professional courses. The capabilities of problem-analyzing, problem-solving, decision-making of the students will be greatly improved from graduation design. 


\section{REFERENCES}

[1] Chen Dongsheng. Graduation topics and ability. Electric Higher Education, 1994(4) .

[2] Zhang Lihua, Liu Sheng. Nan Experimental research of University Students' Employment Ability Structure and development characteristics. Maritime Education Research, 2005(1) .

[3] $\mathrm{Li}$ jin $\mathrm{Ru}$. Research on training applied talents based on the Competency structure. Dalian University of Technology, 2011.4 .

[4] $\mathrm{Bu}$ Yuhuan. Cultivation of students' comprehensive ability in graduation design of Engineering colleges .Petroleum Education, 2007(3) . 